\title{
Bone bruise in anterior cruciate ligament rupture entails a more severe joint damage affecting joint degenerative progression
}

\author{
Giuseppe Filardo $^{3}$ - Luca Andriolo ${ }^{1}$ - Giorgio di Laura Frattura ${ }^{2}(-)$. Francesca Napoli ${ }^{2}$. Stefano Zaffagnini ${ }^{1}$. \\ Christian Candrian ${ }^{2}$
}

Received: 15 November 2017 / Accepted: 30 May 2018 / Published online: 5 June 2018

(c) The Author(s) 2018

\begin{abstract}
Purpose During anterior cruciate ligament (ACL) injury, the large external forces responsible for ligament rupture cause a violent impact between tibial and femoral articular cartilage, which is transferred to bone resulting in bone bruise detectable at MRI. Several aspects remain controversial and await evidence on how this MRI finding should be managed while addressing the ligament lesion. Thus, the aim of the present review was to document the evidence of all available literature on the role of bone bruise associated with ACL lesions.

Methods A systematic review of the literature was performed on bone bruise associated with ACL injury. The search was conducted in September 2017 on three medical electronic databases: PubMed, Web of Science, and the Cochrane Collaboration. Preferred Reporting Items for Systematic Reviews and Meta-analysis (PRISMA) guidelines were used. Relevant articles were studied to investigate three main aspects: prevalence and progression of bone bruise associated with ACL lesions, its impact on the knee in terms of lesion severity and joint degeneration progression over time and, finally, the influence of bone bruise on patient prognosis in terms of clinical outcome.

Results The search identified 415 records and, after an initial screening according to the inclusion/exclusion criteria, 83 papers were used for analysis, involving a total of 10,047 patients. Bone bruise has a high prevalence ( $78 \%$ in the most recent papers), with distinct patterns related to the mechanism of injury. This MRI finding is detectable only in a minority of cases the first few months after trauma, but its presence and persistence have been correlated to a more severe joint damage that may affect the degenerative progression of the entire joint, with recent evidence suggesting possible effects on long-term clinical outcome.

Conclusion This systematic review of the literature documented a growing interest on bone bruise associated with ACL injury, highlighting aspects which could provide to orthopaedic surgeons evidence-based suggestions in terms of clinical relevance when dealing with patients affected by bone bruise following ACL injury. However, prospective long-term studies are needed to better understand the natural history of bone bruise, identifying prognostic factors and targets of specific treatments that should be developed in light of the overall joint derangements accompanying ACL lesions.
\end{abstract}

Levels of evidence IV, Systematic review of level I-IV studies.

Keywords Bone bruise $\cdot$ Bone contusion $\cdot \mathrm{ACL} \cdot$ Knee

Giorgio di Laura Frattura

giorgiodilaura@gmail.com

$1 \quad$ II Orthopaedic and Traumatologic Clinic, Rizzoli Orthopaedic Institute, Via di Barbiano, 1/10, Via G. C. Pupilli, 1, 40136 Bologna, Italy

2 Ospedale Regionale di Lugano, EOC, Via Tesserete, 46, Lugano, Switzerland

3 Nano-Biotechnology Laboratory, Rizzoli Orthopaedic Institute, Via di Barbiano, 1/10, Bologna, Italy

\section{Introduction}

The large external forces responsible for anterior cruciate ligament (ACL) rupture also cause a violent impact between tibial and femoral articular cartilage, which is transferred to bone and results in bone bruise [60, 70, 80]. Such MRI finding is best diagnosed on fluid-sensitive sequences such as T2-weighted images showing increased signal intensity, with or without decreased signal intensity on T1-weighted images. In addition, short tau inversion recovery (STIR) 
sequences can provide more sensitive information by suppressing the signal from normal medullary fat $[55,62]$. Sensitivity and specificity of MRI detection have already been documented to be $83 / 96$ and $86 / 96 \%$, respectively. Moreover, histological studies allowed to correlate these MRI findings to tissue alterations, including microfracture of the subarticular spongiosa, with osteocyte necrosis and empty lacunae, bleeding in the fatty marrow and edema $[55,62]$. Bone bruise associated with ACL rupture has been extensively investigated [62, 63], but several aspects remain controversial and await evidence on how this MRI finding should be managed while addressing the ligament lesion.

The aim of this systematic review was to document the available evidence on bone bruise associated with ACL lesions, investigating its prevalence and progression, as well as the impact on joint and prognosis, with the hypothesis that bone bruise can influence knee degeneration and patient clinical outcome. This would provide orthopaedic surgeons with evidence-based suggestions in terms of clinical relevance when dealing with patients affected by bone bruise following ACL injury.

\section{Materials and methods}

A systematic review of the literature was performed on bone bruise associated with ACL injury. This search was conducted on September 4th, 2017, using the following string on three medical electronic databases, PubMed, Web of Science, and the Cochrane Collaboration: [(subchondral edema) OR (bone bruise) OR (bone marrow edema) OR (bone marrow lesion) OR (bone contusion)] AND [(ACL) OR (anterior cruciate ligament)]. The Preferred Reporting Items for Systematic Reviews and Meta-analysis (PRISMA) guidelines were used [65] (Fig. 1). Two independent authors separately performed the screening process according to preset inclusion and exclusion criteria, study analysis and data tabulation. A final literature summary was obtained by consensus, with disagreements solved by discussion with a third reviewer (GdLF, FN and GF).

First, articles were screened by title and abstract according to the following inclusion criteria: clinical reports of any level of evidence, written in English language, with no time limitation, on the association of bone bruise with ACL lesions. Exclusion criteria were articles written in other languages, preclinical or ex vivo studies, reviews, case reports or clinical studies not evaluating prevalence, progression and impact on the joint and on prognosis. Second, the full texts of the selected articles were screened, with further
Fig. 1 PRISMA flowchart of the systematic literature review
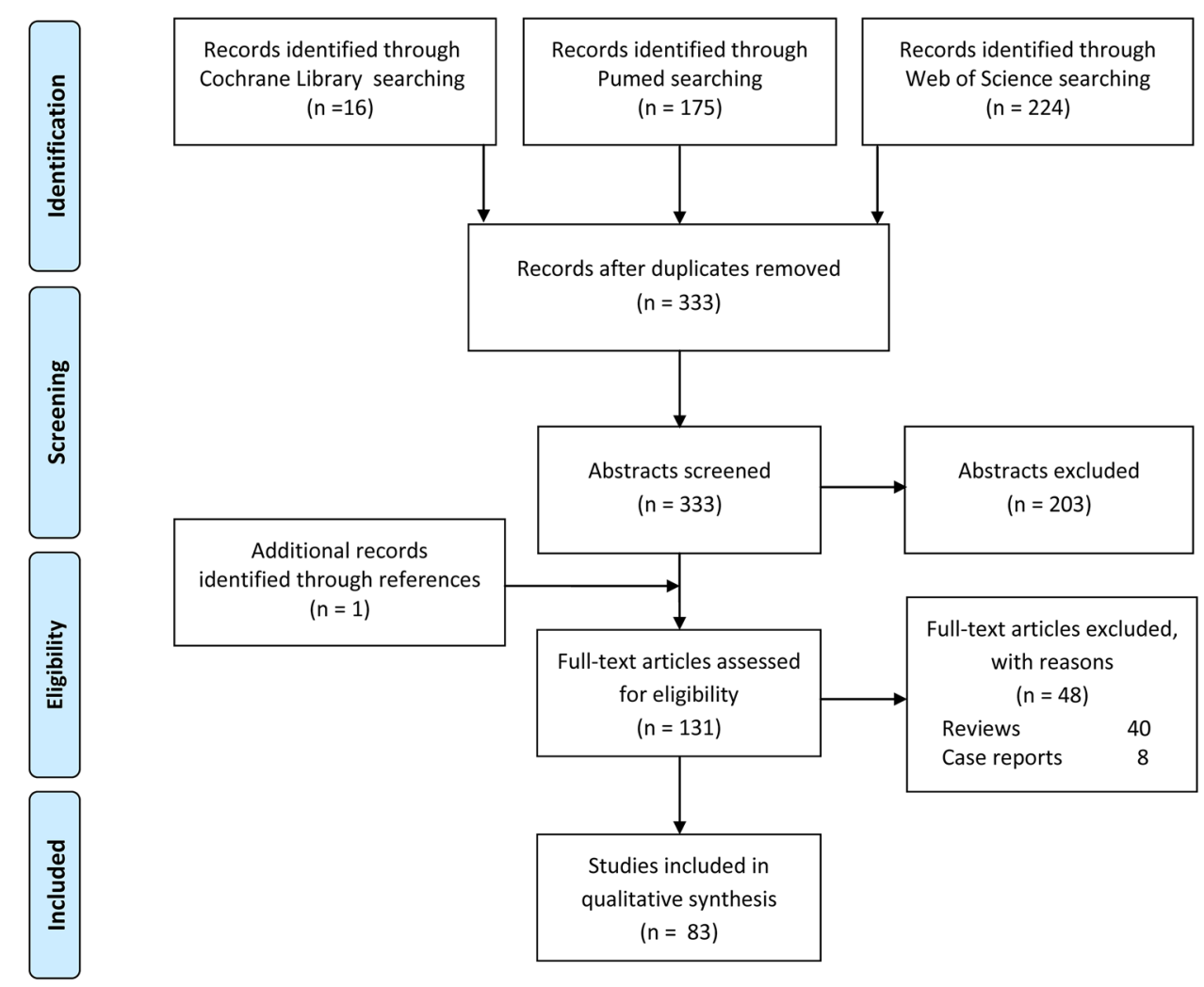
exclusions according to the previously described criteria. Reference lists from the selected papers were also screened. Relevant data (type of study, no of patients and demographics, injury-MRI time and sequence, follow-up, edema size/ grading, edema distribution, prevalence and progression, correlation with other joint lesions and prognosis) were then extracted and collected in a unique database to be analysed for the purposes of the present manuscript. All relevant articles included in this systematic review were studied to investigate three main aspects: the prevalence and progression of bone bruise associated with ACL lesions, its impact on the knee in terms of lesion severity and progression of joint degeneration over time and, finally, the influence of bone bruise on patient prognosis in terms of clinical outcome.

\section{Results}

This systematic review underlined a growing interest on this topic, with an increasing number of papers published over time, more than half in the last 10 years (Fig. 2). The database search identified 83 papers used for the analysis (a detailed study description is reported in Table 1; Fig. 1).

This systematic review revealed heterogeneous MRI sequences and assessment strategies. Bone bruise was quantified in 43/83 studies with the following approaches: scoring systems were used in 9/43 articles, including WORMS, Costa-Paz, ICRS, Lynch, Beattie and Colleagues score and MOAK, while different parameters such as area/volume of the region of interest (either with absolute or percentage values), depth, signal intensity, distribution and diameter were used as criteria in $42 / 43$ cases to quantify bone bruise. These articles analysed heterogeneous populations, for a total of 10,047 patients, including 2,675 females and 4,665 males (in 11 studies sex was not specified) with different sport participation (four articles focusing on athletes, the others on patients with various activity levels). Age ranged from children (only one study), to young adults and to senior patients (5-81 years).

\section{Bone bruise prevalence and progression}

Prevalence of bone bruise ranged from 8 to $98 \%$ (reported in $40 / 83$ papers), being higher in the most recent papers ( $78 \%$ in the last 10 years vs. $62 \%$ in previous papers). Most of the studies also investigated its distribution in the joint compartments, showing a higher prevalence in the lateral side of the knee (52/55), with lateral tibial plateau (31/43) being the most commonly affected site (Fig. 3). The evaluation of progression, investigated in 20 studies (seven retrospective, with heterogeneous follow-ups from 2 weeks to 13 years), documented a wide time range: from series showing complete resolution at 2 months, to others documenting persistence of subchondral marrow changes in $65 \%$ of the cases at 1 year, or even an increase of bone bruise in one-third of the patients over time.

Some factors were reported to influence frequency, distribution, and progression of bone bruise. Female sex, high BMI, complete vs. partial ACL tears and combined lesions were correlated to higher prevalence, while specific distribution patterns were influenced by injury mechanism, such as pivoting (more lateral), hyperextension (more anterior), motor vehicles accident and patellar dislocation (more anterior with patella involvement), as well as by gender and age (female and older patients presented more lateral lesions). Finally, progression was also influenced by some factors, with slower resolution in the presence of osteochondral

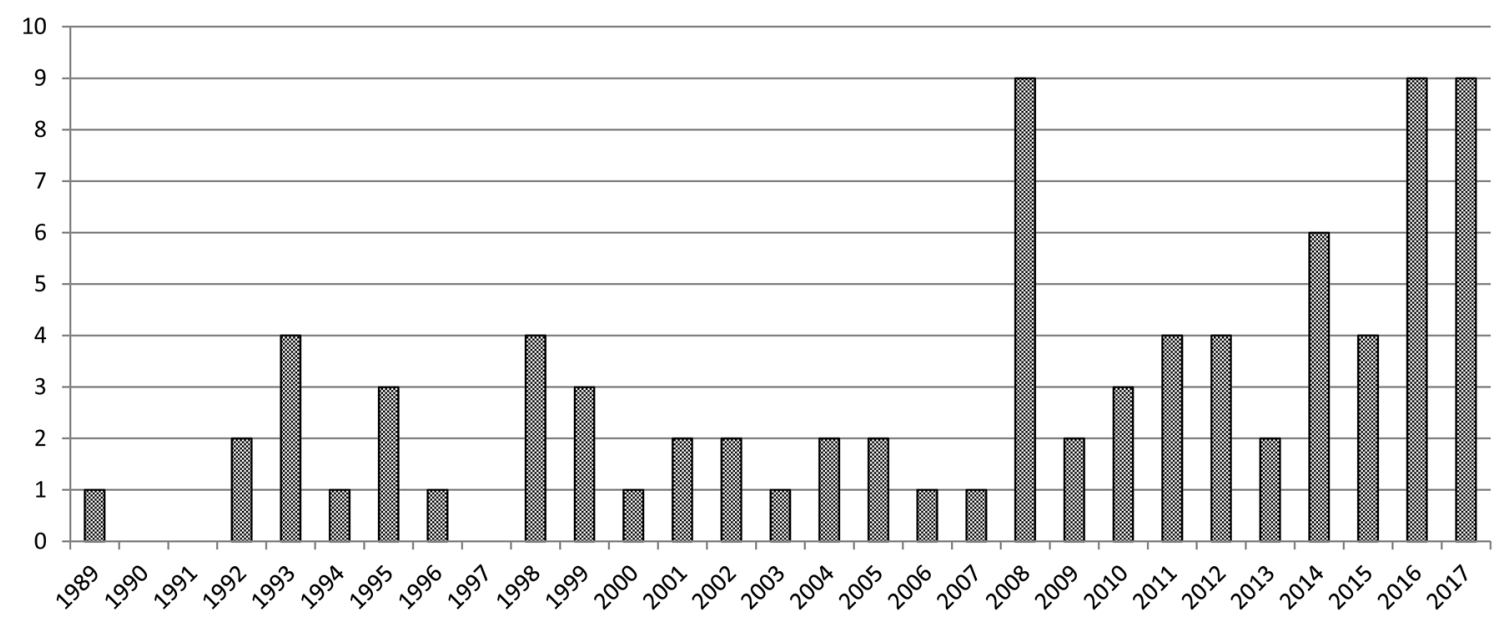

Fig. 2 The analysis of publications per year shows growing interest on bone bruise in ACL lesions with an increasing number of published studies over time 


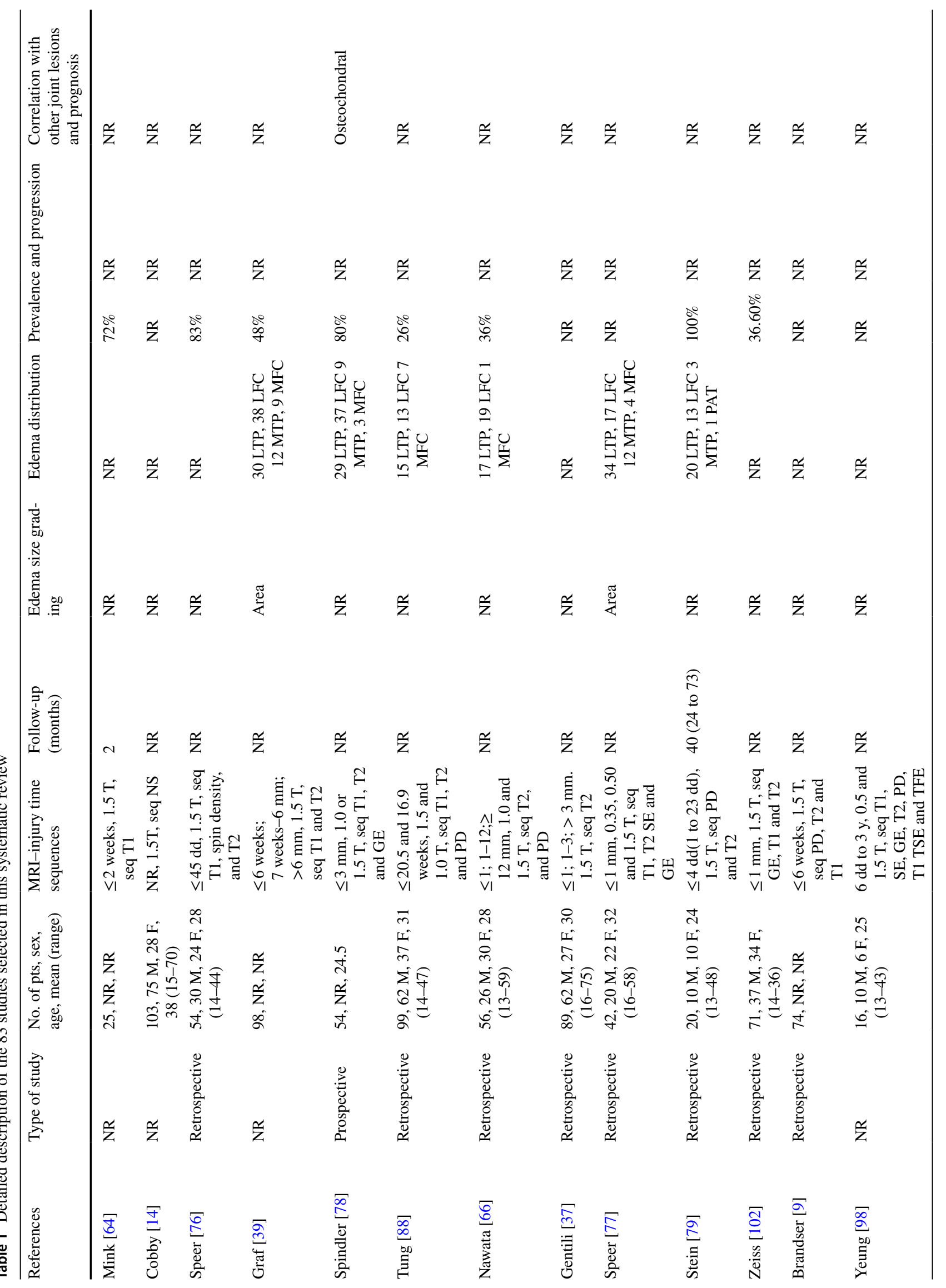




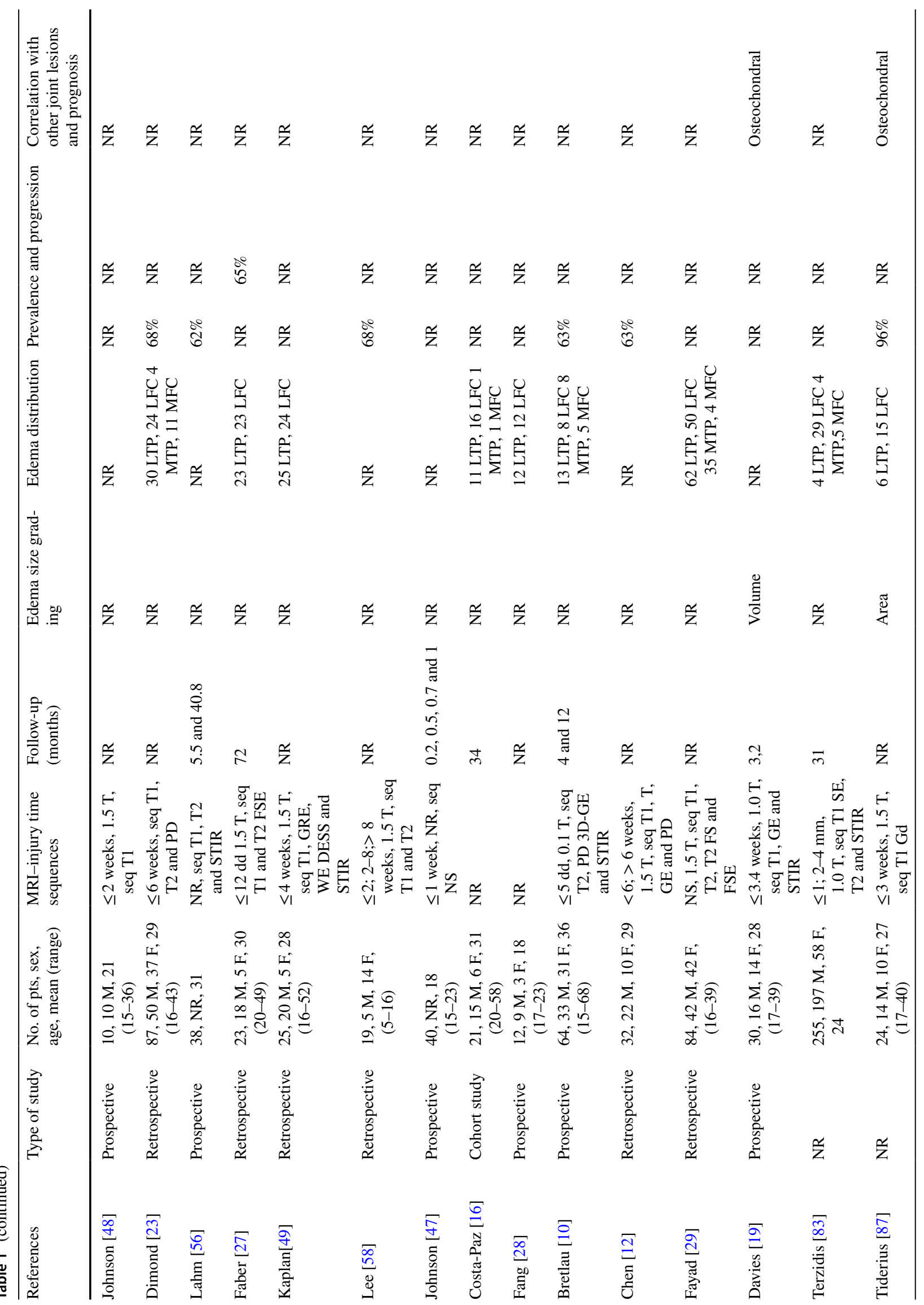




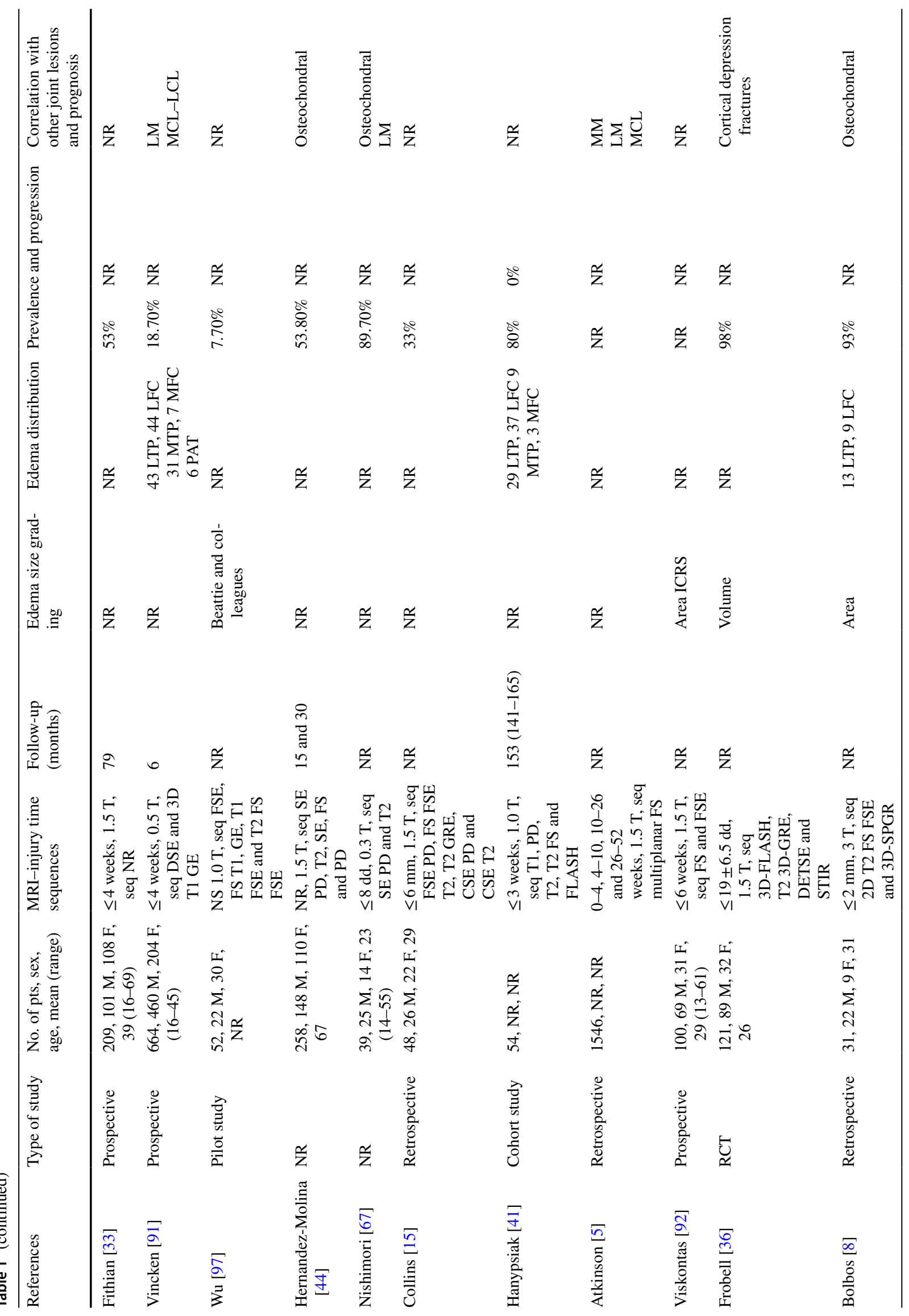




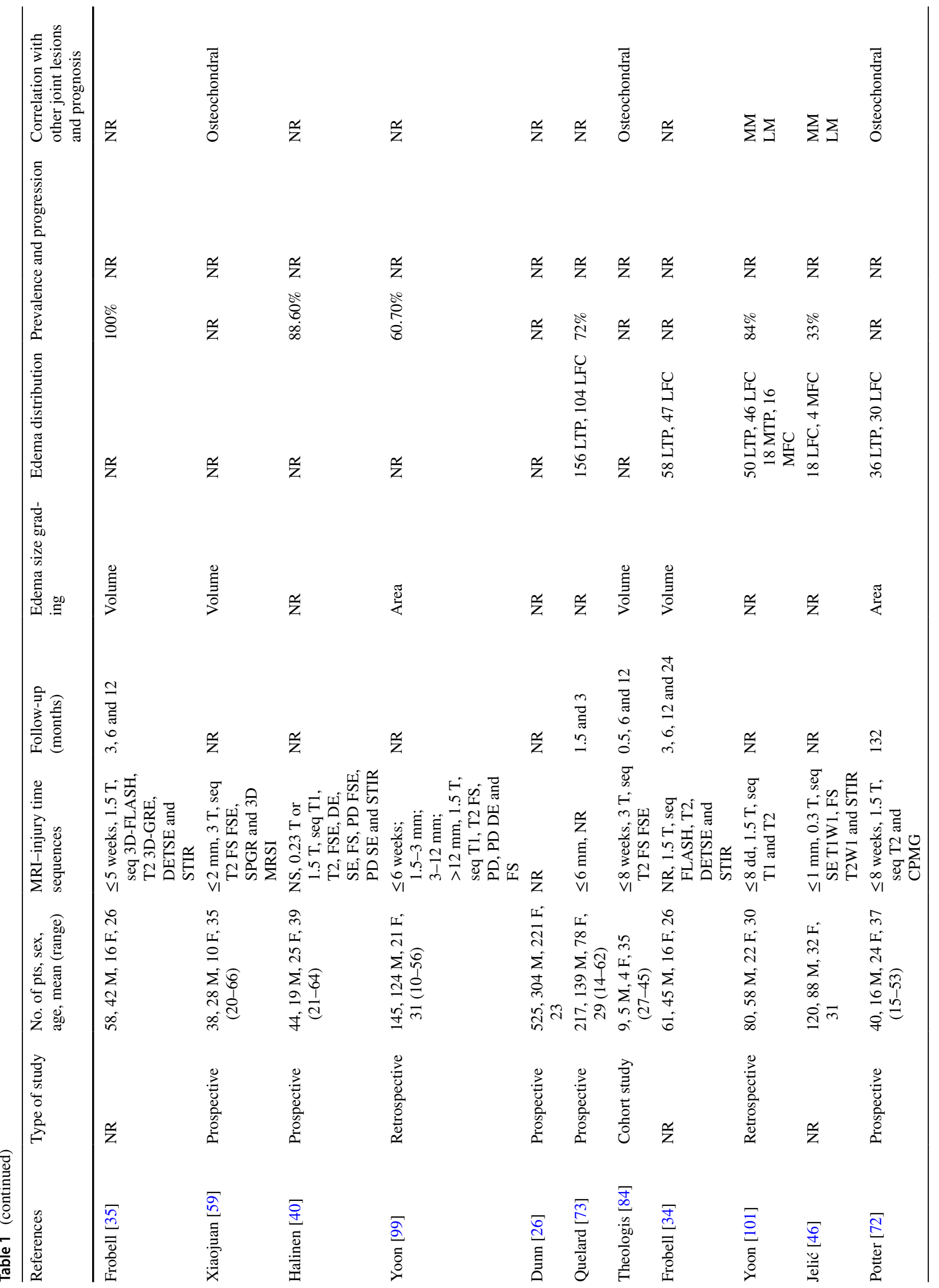




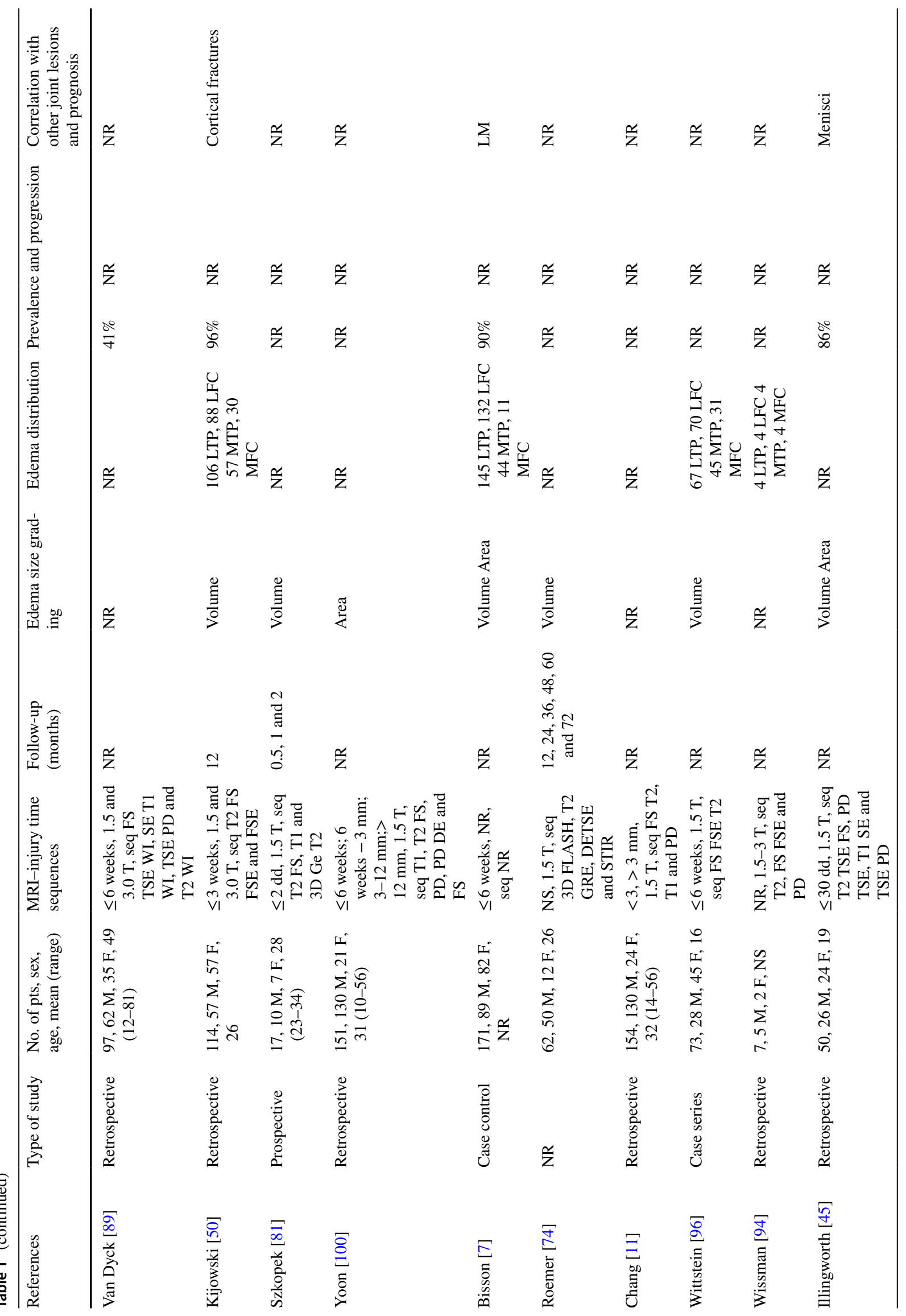




\begin{tabular}{|c|c|c|c|c|c|c|c|c|c|c|c|c|c|}
\hline 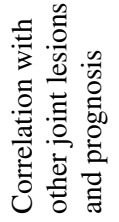 & 号 & 号 & $\begin{array}{l}\bar{\pi} \\
\bar{U} \\
\overline{0} \\
\overline{0} \\
\frac{0}{0} \\
0\end{array}$ & 吕 & 号 & 号 & $\sum \vec{\Sigma}$ & 号 & 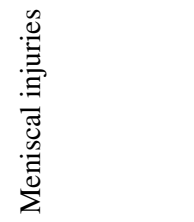 & 吕 & 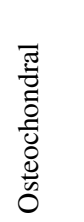 & 吕 & $\sum_{j}$ \\
\hline $\begin{array}{l}.0 \\
.0 \\
0 \\
0 \\
0 \\
0 \\
0 \\
0 \\
0 \\
0 \\
0 \\
0 \\
0\end{array}$ & 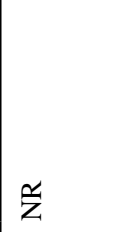 & 号 & 䂟 & 足 & $\frac{\alpha}{z}$ & $\frac{o r}{z}$ & $\frac{\alpha}{z}$ & 号 & 足 & 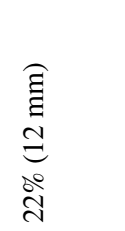 & 孚 & 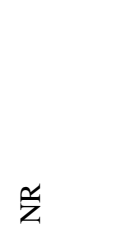 & 孚 \\
\hline 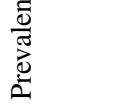 & $\begin{array}{l}\stackrel{0}{0} \\
\text { مे } \\
\text { చి }\end{array}$ & 兑 & 号 & 号 & $\frac{a}{z}$ & $\begin{array}{l}\stackrel{\circ}{0} \\
\hat{n} \\
i n \\
n\end{array}$ & 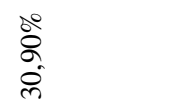 & 号 & $\frac{a}{z}$ & $\tilde{z}$ & $\frac{a}{z}$ & 号 & 足 \\
\hline 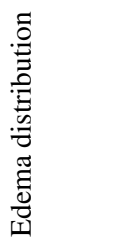 & 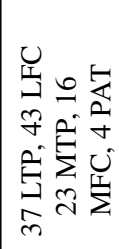 & $\frac{\alpha}{z}$ & 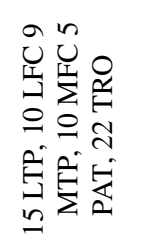 & 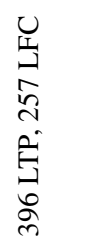 & 号 & 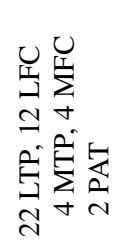 & ž & 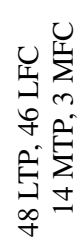 & 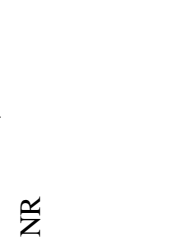 & 兑 & 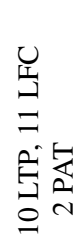 & 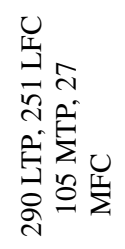 & 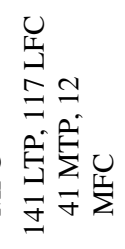 \\
\hline 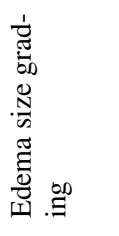 & 光 & 吕 & 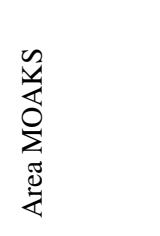 & $\stackrel{\mathscr{J}}{\dot{L}}$ & 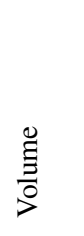 & 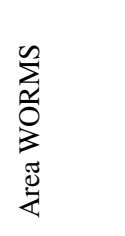 & 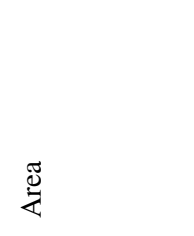 & $\frac{a}{z}$ & 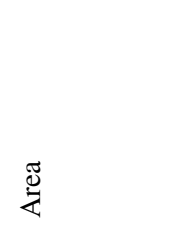 & 迎 & $\underset{\mathscr{J}}{\mathscr{L}}$ & 号 & 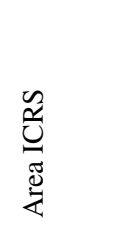 \\
\hline 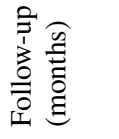 & 艺 & 号 & $\simeq$ & 号 & 号 & $\triangleright$ & $I$ & 孚 & 号 & 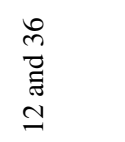 & $\simeq$ & 吕 & 号 \\
\hline 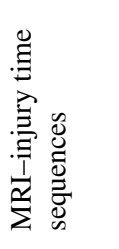 & 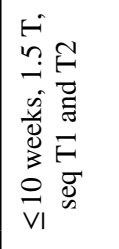 & 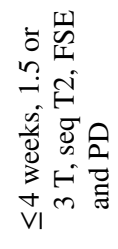 & 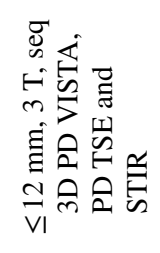 & 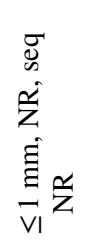 & 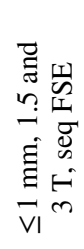 & 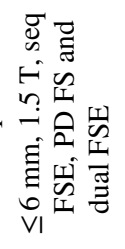 & 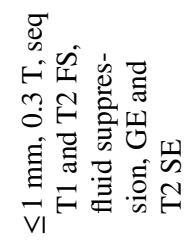 & 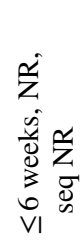 & 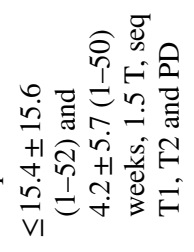 & 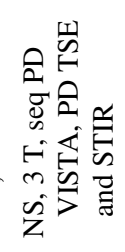 & 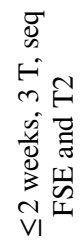 & 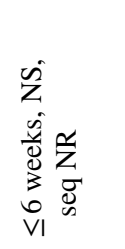 & 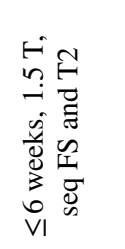 \\
\hline 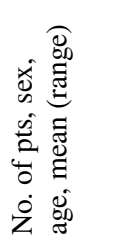 & 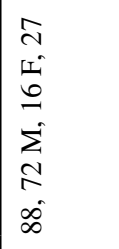 & 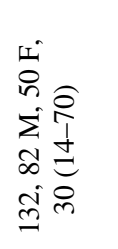 & 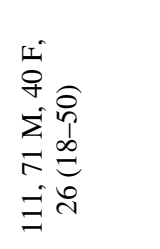 & $\begin{array}{l}\text { ते } \\
\text { ñ } \\
\text { हे }\end{array}$ & 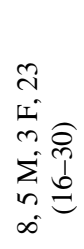 & $\begin{array}{l}\text { ci } \\
0 \\
m \\
\sum_{\infty} \\
\infty \\
0 \\
j=j\end{array}$ & 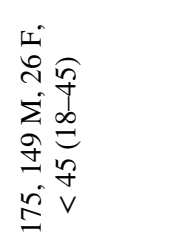 & 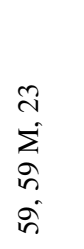 & 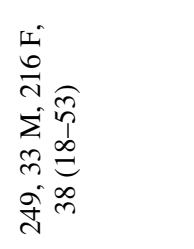 & 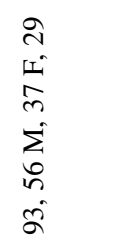 & 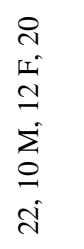 & 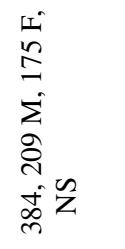 & 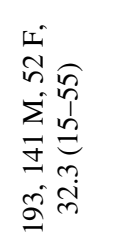 \\
\hline 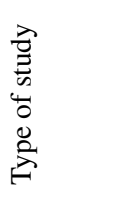 & 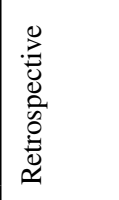 & 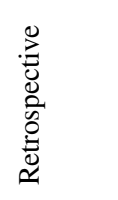 & 兑 & 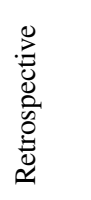 & 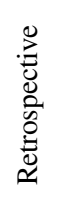 & 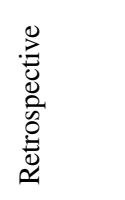 & 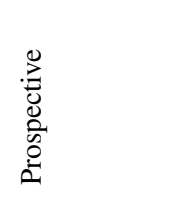 & 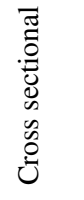 & 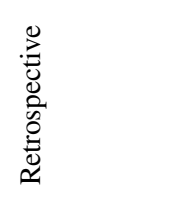 & 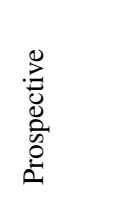 & 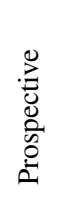 & 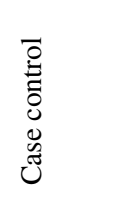 & 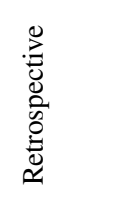 \\
\hline & $\underset{\text { 光 }}{\stackrel{m}{\Xi}}$ & 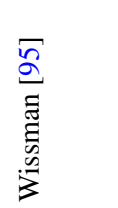 & 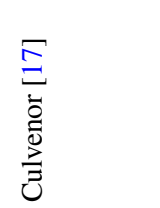 & 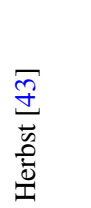 & $\begin{array}{l}\overline{\sqrt{n}} \\
\text { 递 }\end{array}$ & 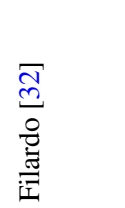 & 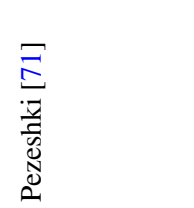 & 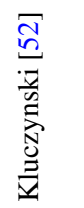 & $\underset{\Xi}{\Xi}$ & 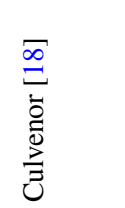 & 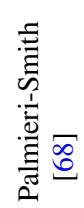 & 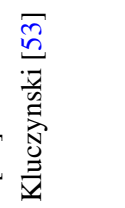 & 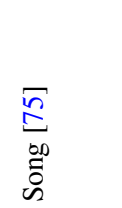 \\
\hline
\end{tabular}




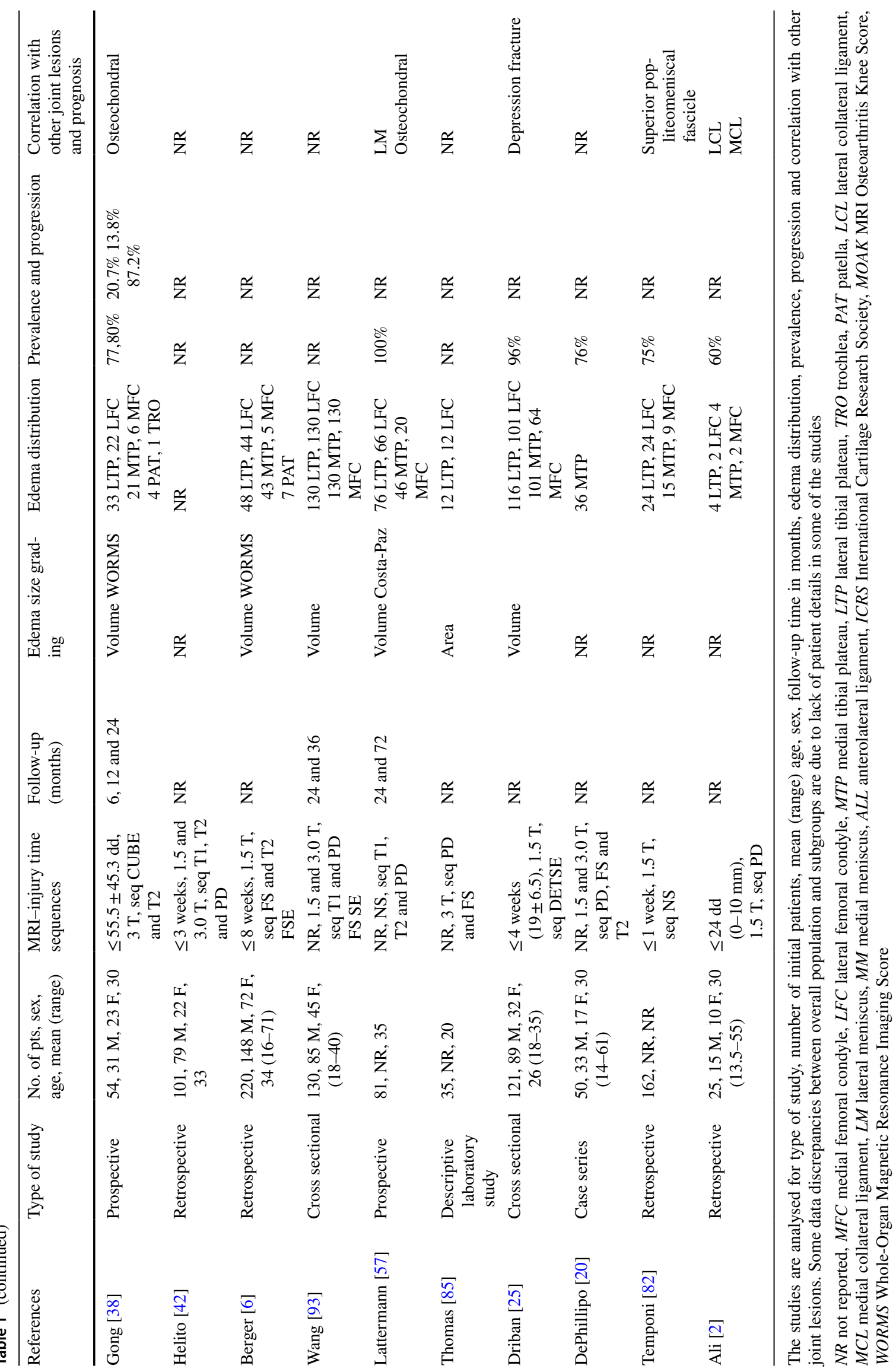




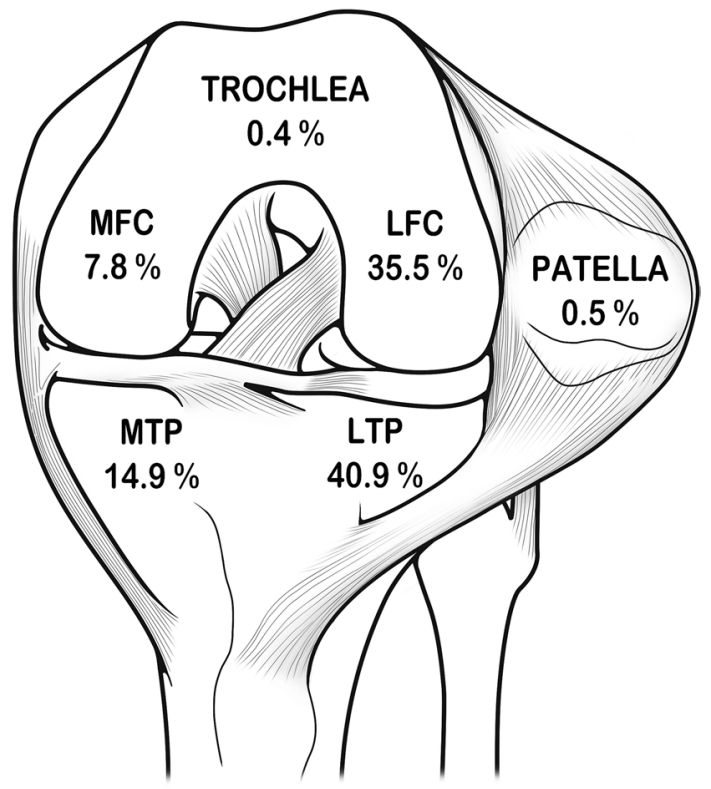

Fig. 3 Percentage of bone bruise distribution in the affected anatomic bone locations. $L T P$ lateral tibial plateau, $L F C$ lateral femoral condyle, MTP medial tibial plateau, $M F C$ medial femoral condyle

lesions and after ACL reconstruction compared to more conservative treatments.

\section{Impact of bone bruise on joint lesion severity and progression}

The severity of joint lesions, investigated in 30/83 studies, was correlated to the presence of bone bruise in 26/30 studies. The most affected tissue was cartilage: osteochondral lesions were reported to correlate significantly in $11 / 13$ studies, ranging from $59 \%$ to more than $80 \%$ of patients $(80 \%$ in the lateral tibial plateau or $94 \%$ in the lateral femoral condyle) affected by bone bruise; this was followed by meniscus lesions and, less frequently, by collateral ligaments and presence of fractures. Some reports also suggested a possible correlation with other lesions, such as those involving the anterolateral ligament, superior popliteomeniscal fascicle, as well as more abundant and slower resolving effusion. The rim sign, with anteromedial bone bruise distribution, was reported to be associated with greater joint derangement. Moreover, the presence of a $>1.5 \mathrm{~mm}$ notch sign, a bone depression due to more frequent impaction at the lateral femoral condyle after pivoting lesions, was reported to be associated with cartilage lesions and lateral meniscus tears. Finally, few studies evaluated articular samples showing softening, fissuring, with degeneration of chondrocytes and loss of proteoglycans, together with necrosis of osteocytes and empty lacunae in subchondral bone, as well as elevation of COMP degradative fragments, both at cartilage and synovial fluid level. Homeostatic alterations were also supported by changes of synovial fluid, which presented a higher presence of glycosaminoglycans. The impact of bone bruise on joint damage over time was explored, showing (4/8 papers) a correlation of bone bruise with persisting and progressive damage of the articular surface, suggesting early OA development [28].

Factors influencing lesion severity of joints presenting bone bruise were found in 20 studies, the most frequent being higher bone bruise size and severity, followed by taller patients and higher BMI. A larger bone bruise was also correlated with osteochondral lesion progression.

\section{Influence of bone bruise on the clinical outcome}

Papers evaluating the influence of bone bruise on clinical outcome (19/83) studied 2822 patients, with a follow-up ranging from 1 week to 13 years. Several methods were used: subjective scoring systems, such as KOOS, Tegner, IKDC, SF-36; ADL, Lysholm, Noyes, and VAS, and other evaluation methods including ROM, clinical examination, and gait analysis.

Among these studies, five focused on baseline clinical findings, two of them showing a correlation of bone bruise with higher pain and laxity, especially in case of bone bruise with higher volume and at the medial side. Four studies focused on short-term recovery and documented a longer time to reach normal ROM and non-antalgic gait before ligament reconstruction, with a lower clinical outcome for up to 6 months, especially in case of larger size and medial side bone bruise distribution. Ten studies explored the mid-/longterm outcome: only one was able to document the influence of bone bruise on the mid-term clinical outcome, showing a lower return to sport after ACL reconstruction in joints presenting bone bruise at baseline MRI.

Finally, factors found to influence clinical findings were associated chondral lesions and osteochondral fractures, as well as bone bruise severity, location (lateral distribution with higher instability and ROM limitation, medial distribution with higher pain) and persistence over time; bone bruise detected at MRI performed more than 3 months after trauma was suggestive of a more difficult return to full activity recovery.

\section{Discussion}

The most important finding of this systematic review of the literature is that bone bruise in ACL lesions is a frequently detected MRI finding that entails a more severe joint damage affecting joint degenerative progression.

Several articles have been published over the past 30 years and the interest on this topic is still growing, with 
an increasing number of studies in the recent past. Nonetheless, the contribution of the existing literature is limited, as most of the findings are accompanied by still open questions, which will be addressed in the following paragraphs. The first factor hindering the possibility to effectively summarize the study results is the lack of a common language in the literature. In fact, besides the overall accepted definition of bone bruise, when looking at lesion assessment and description, the literature showed no common strategy. The sequences used differed among studies, and half of the authors did not even describe the MRI findings observed. Moreover, those who aimed at further assessing the presence of bone bruise, applied heterogeneous methods relying on different grading systems or quantifying area or volume in the affected compartment in either absolute or relative values. The complexity of this scenario is further increased by the heterogeneity of the populations analysed, as well as outcomes and follow-up times investigated. In this light, the evidence on each specific aspect (prevalence, natural history and impact on joint and outcome) is often driven only by few low-quality studies, which explains the current persisting effort of physicians and researchers to further explore the role of bone bruise in ACL lesions.

Prevalence of bone bruise in the MRI of patients affected by ACL lesions has been investigated in most of the selected studies, showing a wide range from 12 to $96 \%$. This heterogeneity can be explained by several factors, such as the differences of the analysed populations in terms of bone bruise joint distribution, mechanism of trauma, age, sex, activity and BMI. Among all, the main factor was the resolution time of the abnormal MRI signal, which makes the presence of bone bruise strongly related to the time passed from injury to MRI examination. To this regard, it is also interesting to observe how the reported prevalence increased in the past few years, which could be explained by different patients included but, possibly, also by the evolution of the MRI technology and sequences. While earlier reports tended to show a swift complete resolution, more recent findings show persistence or even increase of MRI abnormality over time [36]. However, if from one side, modern MRI can allow a more in-depth study of tissue alterations compared to earlier studies; on the other hand, the clinical significance of this more subtle, but now detectable changes, still remains controversial [62].

This systematic review evidenced several questions remaining still open, but at the same time it showed an increasing awareness on the importance of bone bruise. The attention on this matter can be better understood looking at the impact of ALC lesions on society: ACL reconstruction is one of the most common procedures in orthopaedics [61]. Associated injuries and earlier onset of degenerative changes influence the affected knee: high rate (from 10 to 90\%) of osteoarthritis development after ACL injury has been reported despite continuous efforts to optimize ACL treatment [69]. This has prompted researchers to look at possible factors affecting the evolution of joint degeneration.

A correlation between bone bruise and cartilage lesions has been demonstrated, and it is well acknowledged that the presence of cartilage lesions increases with the time elapsed between ACL rupture and reconstruction: chondral lesions may increase the chances of osteoarthritis development, even after ACL surgical repair [30]. Even though in most cases normal cartilage is initially found during arthroscopy, the osteochondral unit absorbs compression forces during impaction, and this could cause a double long-term mechanism of damage of the articular surface. Cartilage metabolism may be significantly affected, with long-term consequences [24]. Moreover, abnormality [86] of subchondral bone may precede and favour cartilage destruction, since the rigid callus resulting from bone fracture may cause cartilage to absorb more of the load force, with abnormal stresses leading to a progressive degeneration of the articular surface [62]. In ACL reconstructed knees, the cartilage overlying the area of bone bruise presents signs of damage with altered extracellular matrix: cartilage evaluated at 12 months' follow-up with recent MRI sequences showed elevated T1 $\rho$ values compared to the surrounding tissue, thus suggesting that despite the resolution of abnormal bone signal, cartilage lesions persist [84]. These imaging data have been confirmed by histological data, and the analysis of joint samples documented an alteration of the entire joint homeostasis [87].

Bone bruise in ACL injury is correlated with osteochondral lesions that can act as a catalyst for osteoarthritis even after a successful reconstruction. In this light, it appears logical to suppose that such an important trauma causing these deleterious consequences on joint tissues might also affect clinical prognosis. However, results on this matter are controversial $[32,67]$. The lack of evidence on the correlation between the presence of bone bruise at MRI after trauma and the long-term effect on the joint with the reconstructed ACL may be explained by several factors, starting from the lack of long-term studies, which could better detect the effect on the joint of the cascade started with the initial trauma [32]. Moreover, current classification systems contribute little towards the understanding of the underlying pathology defined as bone bruise. Relatively less severe trauma causes marrow edema without injury to cells and subchondral bone architecture. However, when the extent of trauma is bigger, trabecular fractures and haemorrhage are seen together with edema, but current MRI sequences and bone bruise definition do not help in distinguishing between these two patterns [62]. Similarly, it is not always easy to distinguish between bone bruise involving only the marrow with occult fractures not breaching the adjacent cortex, and those involving the osteochondral surface. Moreover, factors predictive of subsequent trabecular fracture development have not been 
identified yet. In fact, even bone bruise without cortical disruption may represent a region of bone at increased risk for the subsequent development of insufficiency fractures, if bone is not adequately protected during trabecular healing.

Some efforts have been made to identify predicting factors, such as the importance of the localization of the imaging finding and its evolution pattern, with resolution proceeding from periphery to joint margin (opposite to lesions proceeding toward the centre of bone bruise lesion) being suggested to be associated with osteochondral injuries. However, these correlations are mainly related to sporadic evidence $[19,34,55,90]$. In fact, most of the studies do not address the different evolution patterns according to possible influencing variables, but rather report overall outcomes on heterogeneous populations. The lack of focus on specific patient populations is another aspect that may hinder a better understanding of the long-term clinical impact, since joint tissue damage can variably affect patients with a different activity level [32].

Prospective studies are needed to look at the natural history of bone bruise and at identifying factors affecting its radiological and clinical course. At the moment, clinical management remains complicated, both because it is very difficult to identify specific clinical signs and symptoms due to concomitant knee damages (soft tissue lesions and effusion), and because of the lack of correlation between symptoms and imaging findings. Imaging resolution is largely delayed compared to clinical symptomatology [4], which currently guides clinical management. The understanding of whether and how to protect cartilage (by rest from weight bearing) during initial treatment, when cartilage lacks support from bruised bone $[21,54,55]$, or the development of treatments to address both stiffer long-term tissue repair and altered homeostasis [3, 22, 31], would likely contribute to overall better results.

During ACL injury, the entire joint undergoes a highenergy trauma, which may alter joint homeostasis and longterm prognosis. In this light, even if no statistical analysis was feasible due to the heterogeneity of the included studies, this systematic review provides evidence-based insights to understand the significance of this articular derangement, which can be of clinical relevance for the orthopaedic surgeon when dealing with patients affected by bone bruise following ACL injury, by underlining that this MRI finding may play an important role in the joint derangement affecting the outcome ACL reconstruction surgery. Future research should aim at better understanding clinical significance, factors predicting resolution or long-term consequences to the affected joint and patient prognosis and, finally, at identifying strategies to restore the overall joint homeostasis rather than just the ligament lesion. This would optimize the management of ACL-injured patients with better long-term results.

\section{Conclusion}

Bone bruise has a high prevalence, with distinct patterns related to the mechanism of injury, and its presence and persistence have been correlated to a more severe joint damage, which may affect the degenerative progression of the entire joint, with recent evidence suggesting possible effects on the long-term clinical outcome. However, prospective long-term studies are needed to better understand the natural history of bone bruise, identifying prognostic factors and targets of specific treatments that could be developed in light of the overall joint derangements accompanying ACL lesions.

Funding There is no funding source.

\section{Compliance with ethical standards}

Conflict of Interest The authors declare that they have no conflict of interest.

Ethical approval This article does not contain any studies with human participants or animals performed by any of the authors.

Informed consent For this type of study formal consent is not required.

Open Access This article is distributed under the terms of the Creative Commons Attribution 4.0 International License (http://creativeco mmons.org/licenses/by/4.0/), which permits unrestricted use, distribution, and reproduction in any medium, provided you give appropriate credit to the original author(s) and the source, provide a link to the Creative Commons license, and indicate if changes were made.

\section{References}

1. Ahn JH, Jeong SH, Kang HW (2016) Risk factors of falsenegative magnetic resonance imaging diagnosis for meniscal tear associated with anterior cruciate ligament tear. Arthroscopy 32:1147-1154

2. Ali AM, Pillai JK, Gulati V, Gibbons CER, Roberton BJ (2017) Hyperextension injuries of the knee: do patterns of bone bruising predict soft tissue injury? Skelet Radiol. https://doi. org/10.1007/s00256-017-2754-y

3. Andriolo L, Di Matteo B, Kon E, Filardo G, Venieri G, Marcacci M (2015) PRP augmentation for ACL reconstruction. Biomed Res Int 2015:371746

4. Ariyoshi M, Nagata K, Sato K, Kubo M, Hiraoka K, Hamada $\mathrm{T}$ et al (1997) Hemarthrosis of the knee and bone contusion. Kurume Med J 44:135-139

5. Atkinson PJ, Cooper TG, Anseth S, Walter NE, Kargus R, Haut RC (2008) Association of knee bone bruise frequency with time postinjury and type of soft tissue injury. Orthopedics 31:440

6. Berger N, Andreisek G, Karer AT, Bouaicha S, Naraghi A, Manoliu A et al (2017) Association between traumatic bone marrow abnormalities of the knee, the trauma mechanism and associated soft-tissue knee injuries. Eur Radiol 27:393-403

7. Bisson LJ, Kluczynski MA, Hagstrom LS, Marzo JM (2013) A prospective study of the association between bone contusion 
and intra-articular injuries associated with acute anterior cruciate ligament tear. Am J Sports Med 41:1801-1807

8. Bolbos RI, Ma CB, Link TM, Majumdar S, Li X (2008) In vivo T1rho quantitative assessment of knee cartilage after anterior cruciate ligament injury using $3 \mathrm{~T}$ magnetic resonance imaging. Invest Radiol 43:782-788

9. Brandser EA, Riley MA, Berbaum KS, el-Khoury GY, Bennett DL (1996) MR imaging of anterior cruciate ligament injury: independent value of primary and secondary signs. AJR Am J Roentgenol 167:121-126

10. Bretlau T, Tuxoe J, Larsen L, Jorgensen U, Thomsen HS, Lausten GS (2002) Bone bruise in the acutely injured knee. Knee Surg Sports Traumatol Arthrosc 10:96-101

11. Chang MJ, Chang CB, Choi JY, Je MS, Kim TK (2014) Can magnetic resonance imaging findings predict the degree of knee joint laxity in patients undergoing anterior cruciate ligament reconstruction? BMC Musculoskelet Disord 15:214

12. Chen WT, Shih TT, Tu HY, Chen RC, Shau WY (2002) Partial and complete tear of the anterior cruciate ligament. Acta Radiol 43:511-516

13. Chin YC, Wijaya R, Chong le R, Chang HC, Lee YH (2014) Bone bruise patterns in knee injuries: where are they found? Eur J Orthop Surg Traumatol 24:1481-1487

14. Cobby MJ, Schweitzer ME, Resnick D (1992) The deep lateral femoral notch: an indirect sign of a torn anterior cruciate ligament. Radiology 184:855-858

15. Collins MS, Unruh KP, Bond JR, Mandrekar JN (2008) Magnetic resonance imaging of surgically confirmed anterior cruciate ligament graft disruption. Skelet Radiol 37:233-243

16. Costa-Paz M, Muscolo DL, Ayerza M, Makino A, Aponte-Tinao L (2001) Magnetic resonance imaging follow-up study of bone bruises associated with anterior cruciate ligament ruptures. Arthroscopy 17:445-449

17. Culvenor AG, Collins NJ, Guermazi A, Cook JL, Vicenzino B, Khan KM et al (2015) Early knee osteoarthritis is evident one year following anterior cruciate ligament reconstruction: a magnetic resonance imaging evaluation. Arthritis Rheumatol 67:946-955

18. Culvenor AG, Collins NJ, Guermazi A, Cook JL, Vicenzino B, Whitehead TS et al (2016) Early patellofemoral osteoarthritis features one year after anterior cruciate ligament reconstruction: symptoms and quality of life at three years. Arthritis Care Res (Hoboken) 68:784-792

19. Davies NH, Niall D, King LJ, Lavelle J, Healy JC (2004) Magnetic resonance imaging of bone bruising in the acutely injured knee-short-term outcome. Clin Radiol 59:439-445

20. DePhillipo NN, Cinque ME, Chahla J, Geeslin AG, Engebretsen L, LaPrade RF (2017) Incidence and detection of meniscal ramp lesions on magnetic resonance imaging in patients with anterior cruciate ligament reconstruction. Am J Sports Med 45:2233-2237

21. Di Martino A, Kon E, Perdisa F, Sessa A, Filardo G, Neri MP et al (2015) Surgical treatment of early knee osteoarthritis with a cell-free osteochondral scaffold: results at 24 months of followup. Injury 46(Suppl 8):S33-S38

22. Di Martino A, Tentoni F, Di Matteo B, Cavicchioli A, Lo Presti M, Filardo $G$ et al (2016) Early viscosupplementation after anterior cruciate ligament reconstruction: a randomized controlled trial. Am J Sports Med 44:2572-2578

23. Dimond PM, Fadale PD, Hulstyn MJ, Tung GA, Greisberg J (1998) A comparison of MRI findings in patients with acute and chronic ACL tears. Am J Knee Surg 11:153-159

24. Donohue JM, Buss D, Oegema TR Jr, Thompson RC Jr (1983) The effects of indirect blunt trauma on adult canine articular cartilage. J Bone Jt Surg Am 65:948-957
25. Driban JB, Lohmander S, Frobell RB (2017) Posttraumatic bone marrow lesion volume and knee pain within 4 weeks after anterior cruciate ligament injury. J Athl Train 52:575-580

26. Dunn WR, Spindler KP, Amendola A, Andrish JT, Kaeding CC, Marx RG et al (2010) Which preoperative factors, including bone bruise, are associated with knee pain/symptoms at index anterior cruciate ligament reconstruction (ACLR)? A multicenter orthopaedic outcomes network (MOON) ACLR cohort study. Am J Sports Med 38:1778-1787

27. Faber KJ, Dill JR, Amendola A, Thain L, Spouge A, Fowler PJ (1999) Occult osteochondral lesions after anterior cruciate ligament rupture. Six-year magnetic resonance imaging follow-up study. Am J Sports Med 27:489-494

28. Fang C, Johnson D, Leslie MP, Carlson CS, Robbins M, Di Cesare PE (2001) Tissue distribution and measurement of cartilage oligomeric matrix protein in patients with magnetic resonance imaging-detected bone bruises after acute anterior cruciate ligament tears. J Orthop Res 19:634-641

29. Fayad LM, Parellada JA, Parker L, Schweitzer ME (2003) MR imaging of anterior cruciate ligament tears: is there a gender gap? Skelet Radiol 32:639-646

30. Filardo G, de Caro F, Andriolo L, Kon E, Zaffagnini S, Marcacci M (2016) Do cartilage lesions affect the clinical outcome of anterior cruciate ligament reconstruction? A systematic review. Knee Surg Sports Traumatol Arthrosc. https://doi.org/10.1007/s0016 7-016-4097-y

31. Filardo G, Kon E, Longo UG, Madry H, Marchettini P, Marmotti A et al (2016) Non-surgical treatments for the management of early osteoarthritis. Knee Surg Sports Traumatol Arthrosc 24:1775-1785

32. Filardo G, Kon E, Tentoni F, Andriolo L, Di Martino A, Busacca $\mathrm{M}$ et al (2016) Anterior cruciate ligament injury: post-traumatic bone marrow oedema correlates with long-term prognosis. Int Orthop 40:183-190

33. Fithian DC, Paxton EW, Stone ML, Luetzow WF, Csintalan RP, Phelan D et al (2005) Prospective trial of a treatment algorithm for the management of the anterior cruciate ligament-injured knee. Am J Sports Med 33:335-346

34. Frobell RB (2011) Change in cartilage thickness, posttraumatic bone marrow lesions, and joint fluid volumes after acute ACL disruption: a two-year prospective MRI study of sixty-one subjects. J Bone Jt Surg Am 93:1096-1103

35. Frobell RB, Le Graverand MP, Buck R, Roos EM, Roos HP, Tamez-Pena J et al (2009) The acutely ACL injured knee assessed by MRI: changes in joint fluid, bone marrow lesions, and cartilage during the first year. Osteoarthr Cartilage 17:161-167

36. Frobell RB, Roos HP, Roos EM, Hellio Le Graverand MP, Buck R, Tamez-Pena J et al (2008) The acutely ACL injured knee assessed by MRI: are large volume traumatic bone marrow lesions a sign of severe compression injury? Osteoarthr Cartilage $16: 829-836$

37. Gentili A, Seeger LL, Yao L, Do HM (1994) Anterior cruciate ligament tear: indirect signs at MR imaging. Radiology 193:835-840

38. Gong J, Pedoia V, Facchetti L, Link TM, Ma CB, Li X (2016) Bone marrow edema-like lesions (BMELs) are associated with higher T1rho and T2 values of cartilage in anterior cruciate ligament (ACL)-reconstructed knees: a longitudinal study. Quant Imaging Med Surg 6:661-670

39. Graf BK, Cook DA, De Smet AA, Keene JS (1993) "Bone bruises" on magnetic resonance imaging evaluation of anterior cruciate ligament injuries. Am J Sports Med 21:220-223

40. Halinen J, Koivikko M, Lindahl J, Hirvensalo E (2009) The efficacy of magnetic resonance imaging in acute multi-ligament injuries. Int Orthop 33:1733-1738 
41. Hanypsiak BT, Spindler KP, Rothrock CR, Calabrese GJ, Richmond B, Herrenbruck TM et al (2008) Twelve-year follow-up on anterior cruciate ligament reconstruction: long-term outcomes of prospectively studied osseous and articular injuries. Am J Sports Med 36:671-677

42. Helito CP, Helito PV, Costa HP, Demange MK, Bordalo-Rodrigues M (2017) Assessment of the anterolateral ligament of the knee by magnetic resonance imaging in acute injuries of the anterior cruciate ligament. Arthroscopy 33:140-146

43. Herbst E, Hoser C, Tecklenburg K, Filipovic M, Dallapozza C, Herbort $\mathrm{M}$ et al (2015) The lateral femoral notch sign following ACL injury: frequency, morphology and relation to meniscal injury and sports activity. Knee Surg Sports Traumatol Arthrosc 23:2250-2258

44. Hernandez-Molina G, Guermazi A, Niu J, Gale D, Goggins J, Amin S et al (2008) Central bone marrow lesions in symptomatic knee osteoarthritis and their relationship to anterior cruciate ligament tears and cartilage loss. Arthritis Rheum 58:130-136

45. Illingworth KD, Hensler D, Casagranda B, Borrero C, van Eck $\mathrm{CF}, \mathrm{Fu}$ FH (2014) Relationship between bone bruise volume and the presence of meniscal tears in acute anterior cruciate ligament rupture. Knee Surg Sports Traumatol Arthrosc 22:2181-2186

46. Jelic D, Masulovic D (2011) Bone bruise of the knee associated with the lesions of anterior cruciate ligament and menisci on magnetic resonance imaging. Vojnosanit Pregl 68:762-766

47. Johnson DL, Bealle DP, Brand JC Jr, Nyland J, Caborn DN (2000) The effect of a geographic lateral bone bruise on knee inflammation after acute anterior cruciate ligament rupture. Am J Sports Med 28:152-155

48. Johnson DL, Urban WP Jr, Caborn DN, Vanarthos WJ, Carlson CS (1998) Articular cartilage changes seen with magnetic resonance imaging-detected bone bruises associated with acute anterior cruciate ligament rupture. Am J Sports Med 26:409-414

49. Kaplan PA, Gehl RH, Dussault RG, Anderson MW, Diduch DR (1999) Bone contusions of the posterior lip of the medial tibial plateau (contrecoup injury) and associated internal derangements of the knee at MR imaging. Radiology 211:747-753

50. Kijowski R, Sanogo ML, Lee KS, Munoz Del Rio A, McGuine TA, Baer GS et al (2012) Short-term clinical importance of osseous injuries diagnosed at MR imaging in patients with anterior cruciate ligament tear. Radiology 264:531-541

51. Kim SY, Spritzer CE, Utturkar GM, Toth AP, Garrett WE, DeFrate LE (2015) Knee kinematics during noncontact anterior cruciate ligament injury as determined from bone bruise location. Am J Sports Med 43:2515-2521

52. Kluczynski MA, Kang JV, Marzo JM, Bisson LJ (2016) Magnetic resonance imaging and intra-articular findings after anterior cruciate ligament injuries in ice hockey versus other sports. Orthop J Sports Med 4:2325967116646534

53. Kluczynski MA, Marzo JM, Rauh MA, Bernas GA, Bisson LJ (2016) A case-control study comparing bone bruising and intraarticular injuries in patients undergoing anterior cruciate ligament reconstruction with and without medial collateral ligament tears. Orthop J Sports Med 4:2325967116660053

54. Kon E, Filardo G, Perdisa F, Venieri G, Marcacci M (2014) Clinical results of multilayered biomaterials for osteochondral regeneration. J Exp Orthop 1:10

55. Kon E, Ronga M, Filardo G, Farr J, Madry H, Milano G et al (2016) Bone marrow lesions and subchondral bone pathology of the knee. Knee Surg Sports Traumatol Arthrosc 24:1797-1814

56. Lahm A, Erggelet C, Steinwachs M, Reichelt A (1998) Articular and osseous lesions in recent ligament tears: arthroscopic changes compared with magnetic resonance imaging findings. Arthroscopy 14:597-604

57. Lattermann C, Jacobs CA, Reinke EK, Scaramuzza EA, Huston LJ, Dunn WR et al (2017) Are bone bruise characteristics and articular cartilage pathology associated with inferior outcomes 2 and 6 years after anterior cruciate. Ligament Reconstruction? Cartilage 8:139-145

58. Lee K, Siegel MJ, Lau DM, Hildebolt CF, Matava MJ (1999) Anterior cruciate ligament tears: MR imaging-based diagnosis in a pediatric population. Radiology 213:697-704

59. Li X, Ma BC, Bolbos RI, Stahl R, Lozano J, Zuo J et al (2008) Quantitative assessment of bone marrow edema-like lesion and overlying cartilage in knees with osteoarthritis and anterior cruciate ligament tear using MR imaging and spectroscopic imaging at $3 \mathrm{~T}$. J Magn Reson Imaging 28:453-461

60. Lynch TC, Crues JV, Morgan FW, Sheehan WE, Harter LP, Ryu $\mathrm{R}$ (1989) Bone abnormalities of the knee: prevalence and significance at MR imaging. Radiology 171:761-766

61. Mall NA, Chalmers PN, Moric M, Tanaka MJ, Cole BJ, Bach BR Jr et al (2014) Incidence and trends of anterior cruciate ligament reconstruction in the United States. Am J Sports Med 42:2363-2370

62. Mandalia V, Fogg AJ, Chari R, Murray J, Beale A, Henson JH (2005) Bone bruising of the knee. Clin Radiol 60:627-636

63. Mathis DT, Hirschmann A, Falkowski AL, Kiekara T, Amsler F, Rasch $\mathrm{H}$ et al (2018) Increased bone tracer uptake in symptomatic patients with ACL graft insufficiency: a correlation of MRI and SPECT/CT findings. Knee Surg Sports Traumatol Arthrosc 26:563-573

64. Mink JH, Deutsch AL (1989) Occult cartilage and bone injuries of the knee: detection, classification, and assessment with MR imaging. Radiology 170:823-829

65. Moher D, Liberati A, Tetzlaff J, Altman DG (2009) Preferred reporting items for systematic reviews and meta-analyses: the PRISMA statement. BMJ 339:b2535

66. Nawata K, Teshima R, Suzuki T (1993) Osseous lesions associated with anterior cruciate ligament injuries. Assessment by magnetic resonance imaging at various periods after injuries. Arch Orthop Trauma Surg 113:1-4

67. Nishimori M, Deie M, Adachi N, Kanaya A, Nakamae A, Motoyama $\mathrm{M}$ et al (2008) Articular cartilage injury of the posterior lateral tibial plateau associated with acute anterior cruciate ligament injury. Knee Surg Sports Traumatol Arthrosc 16:270-274

68. Palmieri-Smith RM, Wojtys EM, Potter HG (2016) Early cartilage changes after anterior cruciate ligament injury: evaluation with imaging and serum biomarkers-a pilot study. Arthroscopy 32:1309-1318

69. Papalia R, Torre G, Vasta S, Zampogna B, Pedersen DR, Denaro $\mathrm{V}$ et al (2015) Bone bruises in anterior cruciate ligament injured knee and long-term outcomes. A review of the evidence. Open Access J Sports Med 6:37-48

70. Patel SA, Hageman J, Quatman CE, Wordeman SC, Hewett TE (2014) Prevalence and location of bone bruises associated with anterior cruciate ligament injury and implications for mechanism of injury: a systematic review. Sports Med 44:281-293

71. Pezeshki S, Vogl TJ, Pezeshki MZ, Daghighi MH, Pourisa M (2016) Association of the type of trauma, occurrence of bone bruise, fracture and joint effusion with the injury to the menisci and ligaments in MRI of knee trauma. Muscles Ligaments Tendons J 6:161-166

72. Potter HG, Jain SK, Ma Y, Black BR, Fung S, Lyman S (2012) Cartilage injury after acute, isolated anterior cruciate ligament tear: immediate and longitudinal effect with clinical/MRI followup. Am J Sports Med 40:276-285

73. Quelard B, Sonnery-Cottet B, Zayni R, Ogassawara R, Prost T, Chambat P (2010) Preoperative factors correlating with prolonged range of motion deficit after anterior cruciate ligament reconstruction. Am J Sports Med 38:2034-2039

74. Roemer FW, Frobell R, Lohmander LS, Niu J, Guermazi A (2014) Anterior cruciate ligament osteoarthritis score 
(ACLOAS): longitudinal MRI-based whole joint assessment of anterior cruciate ligament injury. Osteoarthr Cartilage 22:668-682

75. Song GY, Zhang H, Wang QQ, Zhang J, Li Y, Feng H (2016) Bone contusions after acute noncontact anterior cruciate ligament injury are associated with knee joint laxity, concomitant meniscal lesions, and anterolateral ligament abnormality. Arthroscopy 32:2331-2341

76. Speer KP, Spritzer CE, Bassett FH, Feagin JA Jr, Garrett WE Jr (1992) Osseous injury associated with acute tears of the anterior cruciate ligament. Am J Sports Med 20:382-389

77. Speer KP, Warren RF, Wickiewicz TL, Horowitz L, Henderson L (1995) Observations on the injury mechanism of anterior cruciate ligament tears in skiers. Am J Sports Med 23:77-81

78. Spindler KP, Schils JP, Bergfeld JA, Andrish JT, Weiker GG, Anderson TE et al (1993) Prospective study of osseous, articular, and meniscal lesions in recent anterior cruciate ligament tears by magnetic resonance imaging and arthroscopy. Am J Sports Med 21:551-557

79. Stein LN, Fischer DA, Fritts HM, Quick DC (1995) Occult osseous lesions associated with anterior cruciate ligament tears. Clin Orthop Relat Res 187-193

80. Sutton KM, Bullock JM (2013) Anterior cruciate ligament rupture: differences between males and females. J Am Acad Orthop Surg 21:41-50

81. Szkopek K, Warming T, Neergaard K, Jorgensen HL, Christensen HE, Krogsgaard M (2012) Pain and knee function in relation to degree of bone bruise after acute anterior cruciate ligament rupture. Scand J Med Sci Sports 22:635-642

82. Temponi EF, de Carvalho Junior LH, Saithna A, Thaunat M, Sonnery-Cottet B (2017) Incidence and MRI characterization of the spectrum of posterolateral corner injuries occurring in association with ACL rupture. Skelet Radiol 46:1063-1070

83. Terzidis IP, Christodoulou AG, Ploumis AL, Metsovitis SR, Koimtzis M, Givissis P (2004) The appearance of kissing contusion in the acutely injured knee in the athletes. Br J Sports Med 38:592-596

84. Theologis AA, Kuo D, Cheng J, Bolbos RI, Carballido-Gamio $\mathrm{J}, \mathrm{Ma} \mathrm{CB}$ et al (2011) Evaluation of bone bruises and associated cartilage in anterior cruciate ligament-injured and -reconstructed knees using quantitative $\mathrm{t}(1 \mathrm{rho})$ magnetic resonance imaging: 1-year cohort study. Arthroscopy 27:65-76

85. Thomas AC, Palmieri-Smith RM (2017) Knee frontal-plane biomechanics in adults with or without bone marrow edemalike lesions after anterior cruciate ligament injury. J Athl Train 52:581-586

86. Thompson RC Jr, Oegema TR Jr, Lewis JL, Wallace L (1991) Osteoarthrotic changes after acute transarticular load. An animal model. J Bone Jt Surg Am 73:990-1001

87. Tiderius CJ, Olsson LE, Nyquist F, Dahlberg L (2005) Cartilage glycosaminoglycan loss in the acute phase after an anterior cruciate ligament injury: delayed gadolinium-enhanced magnetic resonance imaging of cartilage and synovial fluid analysis. Arthritis Rheum 52:120-127

88. Tung GA, Davis LM, Wiggins ME, Fadale PD (1993) Tears of the anterior cruciate ligament: primary and secondary signs at MR imaging. Radiology 188:661-667
89. Van Dyck P, Gielen JL, Vanhoenacker FM, Wouters K, Dossche L, Parizel PM (2012) Stable or unstable tear of the anterior cruciate ligament of the knee: an MR diagnosis? Skelet Radiol 41:273-280

90. Vellet AD, Marks PH, Fowler PJ, Munro TG (1991) Occult posttraumatic osteochondral lesions of the knee: prevalence, classification, and short-term sequelae evaluated with MR imaging. Radiology 178:271-276

91. Vincken PW, Ter Braak BP, van Erkel AR, Coerkamp EG, Mallens WM, Bloem JL (2006) Clinical consequences of bone bruise around the knee. Eur Radiol 16:97-107

92. Viskontas DG, Giuffre BM, Duggal N, Graham D, Parker D, Coolican M (2008) Bone bruises associated with ACL rupture: correlation with injury mechanism. Am J Sports Med 36:927-933

93. Wang X, Wang Y, Bennell KL, Wrigley TV, Cicuttini FM, Fortin $\mathrm{K}$ et al (2017) Cartilage morphology at 2-3 years following anterior cruciate ligament reconstruction with or without concomitant meniscal pathology. Knee Surg Sports Traumatol Arthrosc $25: 426-436$

94. Wissman RD, England E, Mehta K, Boateng S, Javadi A, Smith $P$ et al (2014) Patellotibial contusions: a rare cruciate ligament injury pattern. J Comput Assist Tomogr 38:495-498

95. Wissman RD, England E, Mehta K, Burch M, Javadi A, Newton $\mathrm{K}$ (2015) The anteromedial tibial rim sign: an indicator of patellotibial impaction in acute anterior cruciate ligament tears. J Comput Assist Tomogr 39:57-63

96. Wittstein J, Vinson E, Garrett W (2014) Comparison between sexes of bone contusions and meniscal tear patterns in noncontact anterior cruciate ligament injuries. Am J Sports Med 42:1401-1407

97. Wu H, Webber C, Fuentes CO, Bensen R, Beattie K, Adachi JD et al (2007) Prevalence of knee abnormalities in patients with osteoarthritis and anterior cruciate ligament injury identified with peripheral magnetic resonance imaging: a pilot study. Can Assoc Radiol J 58:167-175

98. Yeung KW, Liu GC, Wu DK (1998) Tear of the anterior cruciate ligament: evaluation with MR imaging. Kaohsiung J Med Sci 14:88-93

99. Yoon JP, Chang CB, Yoo JH, Kim SJ, Choi JY, Choi JA et al (2010) Correlation of magnetic resonance imaging findings with the chronicity of an anterior cruciate ligament tear. J Bone Jt Surg Am 92:353-360

100. Yoon JP, Yoo JH, Chang CB, Kim SJ, Choi JY, Yi JH et al (2013) Prediction of chronicity of anterior cruciate ligament tear using MRI findings. Clin Orthop Surg 5:19-25

101. Yoon KH, Yoo JH, Kim KI (2011) Bone contusion and associated meniscal and medial collateral ligament injury in patients with anterior cruciate ligament rupture. J Bone Jt Surg Am 93:1510-1518

102. Zeiss J, Paley K, Murray K, Saddemi SR (1995) Comparison of bone contusion seen by MRI in partial and complete tears of the anterior cruciate ligament. J Comput Assist Tomogr 19:773-776 